\title{
Working in partnership to develop engineering capability in energy efficiency
}

\section{Authors \& Affiliations}

Cheryl Desha ${ }^{a}$ (Corresponding Author), Duane Robinson ${ }^{b}$, Alistair Sproul ${ }^{c}$

a Senior Lecturer, Queensland University of Technology, Room S774, Gardens Point Campus, 2 George Street Brisbane 4001, Queensland, Australia, cheryl.desha@qut.edu.au, +61 731384072.

${ }^{b}$ Senior Lecturer, School of Electrical, Computer \& Telecommunications Engineering, Sustainable Buildings Research Centre, University of Wollongong 2522, New South Wales, Australia, duane@uow.edu.au

${ }^{c}$ Associate Professor, School of Photovoltaic and Renewable Energy Engineering, University of New South Wales, Sydney 2052, New South Wales, Australia, a.sproul@unsw.edu.au

\section{Abstract}

Energy efficiency is a complex topic to integrate into higher education curricula, with limited success internationally or in Australia. This paper discusses one of the successful initiatives within the Energy Efficiency Training Program, which was jointly managed and implemented by the New South Wales Office of Environment and Heritage and Department of Education and Communities. The state government initiative aimed to increase the knowledge and skills of the New South Wales workforce, help business to identify and implement energy efficiency projects, and provide professional development for the training providers. Key sectors targeted included property, construction, manufacturing and services. The Program was externally evaluated over the three years 2011 to 2013 and a range of insights were gained through these facilitated reflective opportunities, confirming and building upon literature on the topic to date. This paper presents lessons learned from the engineering part of the program ('the project'), spanning government agencies, academic institutions, and academia. The paper begins with a contextual summary, followed by a synthesis of key learnings and implications for future training initiatives. It is intended that sharing these lessons will contribute to literature in the field, and assist other organisations in Australia and overseas planning similar initiatives.

\section{Keywords}

Engineering education, Curriculum renewal, Energy efficiency, Capability, Partnership, University 


\section{Introduction - Project Context}

Energy efficiency initiatives are widely recognised as a relatively straightforward and cost effective way to reduce rising greenhouse gas emissions and manage rising energy costs (COAG, 2009a). Implementing these initiatives requires the skills of a number of professions, with engineering clearly identified for some time as playing a critical role (see for example Thomas et al, 2013; Davidson et al, 2010; Velazquez et al, 1999). This is hampered by a lack of skills in identifying and implementing energy efficiency solutions. While governments recognize the need for building capability (for example COAG, 2009b; Fernandez et al, 2013), key professions still lack knowledge and skills in core energy efficiency topic areas, and there is a lag time of up to a decade before undergraduate education influences energy efficiency performance in the workplace (Desha and Hargroves, 2009). In Australia there are still few higher education institutions embedding energy efficiency within their professional degrees (RET, 2012).

With this in mind, it is critical to have a multi-track approach to building capacity to deliver energy efficiency improvements. This includes targeting multiple professions, and targeting those who are currently in the workforce as well as those who are studying for their professional qualification. Situating 'engineering education for energy efficiency' within a wider context, it can be viewed as a sub-topic of the larger topic area of 'engineering education for sustainable development', considering the educational concept of 'rapid curriculum renewal' (Desha and Hargroves, 2014). Education research in this field is focused on timely and systemic integration of rapidly emergent knowledge and skill sets into higher education curricula that is highly regulated.

Numerous authors have published on challenges and opportunities for curriculum renewal towards sustainable development in higher education, as discussed in detail by Desha and Hargroves (2014). Notable examples from the last decade include those referenced in Ashford (2004) and Holmberg and Samuelsson (2006) with regard to drivers and barriers for implementing sustainable development in higher education, in Byrne et al (2013) and Wiek et al (2011) with regard to key competencies in sustainability, in Karatzoglou (2013) with regard to evolving roles and contributions of universities, and in Kastenhofer et al (2010) with regard to the contribution of different modes of learning and teaching within university curricula to foster engineering education for sustainable development. There are also a number of researchers such as Azapagic et al (2005) and Glavic (2006) who have pondered the status-quo of student understanding internationally and within specific disciplines such as chemical engineering, exploring the context described by authors such as Abdul-Wahab et al (2003) on the need for including such education in engineering curriculum. 
In addition, a variety of pedagogical, disciplinary, organizational and policy challenges are discussed by authors such as Lozano (2014) and Svanstrom et al (2012) with regard to program level considerations, Barth and Rieckmann (2012) with regard to using academic staff development to catalyse curriculum renewal, , Segalàs et al (2010) considering the student learning experience, and Allenby et al (2009) with regard to the concept of 'sustainable engineering' and its implications for engineering education. At a course-by-course level individual efforts are documented by authors such as Lehmann et al (2008) who address the role of problem-oriented and projectbased learning, Quist et al (2006) who discuss back-casting as a tool, Boks et al (2006) who consider industrial design engineering, and Lundholm (2004) who considers civil engineering and environmental inclusions.

Within this context, literature on experiences and applications in the sub-topic area of energy efficiency is still relatively emergent. This is despite the clear role of energy efficiency in addressing global challenges such as reducing greenhouse gas emissions, and facilitating a transition to fossil-fuel alternatives (Weisacker et al 2009), and ongoing efforts within higher education institutions to address 'campus greening' and energy improvements (for example Koester et al, 2006; Alshuwaikhat and Abubakar, 2008; Jain et al, 2013).

In Australia, a number of research initiatives have been undertaken over the last several years to explore the specific topic of 'energy efficiency education', understand the state of energy efficiency education for engineering in the higher education sector and to identify specific barriers and opportunities for catalyzing such curriculum renewal. Such studies include national research initiatives for the Ministerial Council's National Framework for Energy Efficiency (NFEE) (Desha and Hargroves, 2009; Desha et al., 2009) and the Federal Department of Resources, Energy and Tourism (RET, 2011a, 2011b, 2012). In summary, energy efficiency education includes curriculum focused on knowledge and skills related to achieving energy performance improvements across the built environment, from residential, commercial and industrial buildings to manufacturing processes, heavy industry, mining and transportation. It includes a whole of system approach to a wide variety of sub-topic areas, spanning enabling and technical knowledge and skills as shown in Figure 1. 


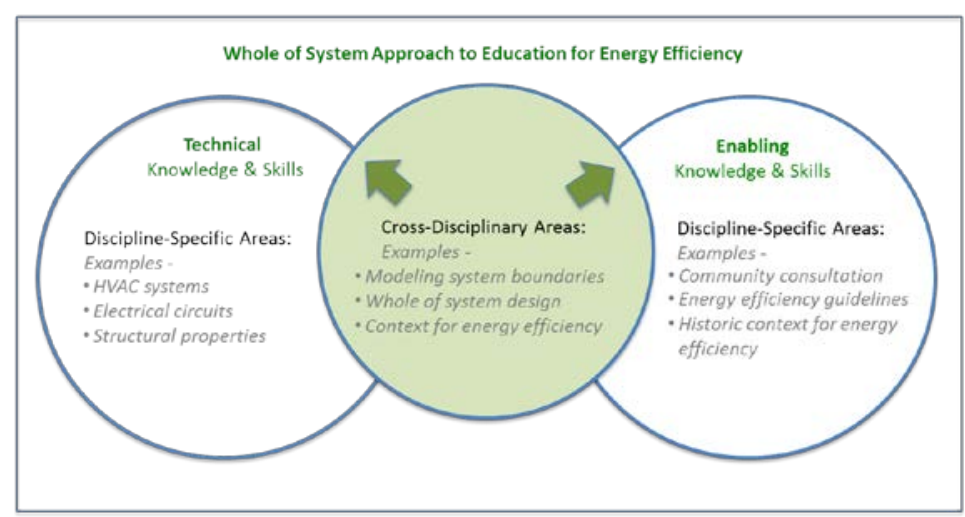

Figure 1. Whole of system approach to energy efficiency education (Figure 2 in RET, 2012)

The results of these investigations suggest that in general the curriculum renewal process to-date has been slow and ad hoc, despite clear signs of the imperative for such curriculum renewal, across government, industry, and academia. Critical to building capability is working in partnerships, whereby government, professional bodies, industry and academia collaborate to harness funding, career advancement and knowledge to undertake curriculum renewal.

With this in mind, this paper focuses on a leading-edge initiative to undertake curriculum renewal in undergraduate, postgraduate, and continuing professional development studies, namely the New South Wales (NSW) state government's Energy Efficiency Training Program. This program was the first Australian state government-led partnership with higher education institutions to deliver energy efficiency related curriculum renewal in engineering. As such, it provided an opportunity for the government to address recommendations from previous research funded by the NFEE, namely that engineering should be a focus for building capabilities to deliver energy efficiency improvements.

The paper begins with an overview of the training program's objectives and deliverables. It then highlights outcomes from the curriculum renewal process, including the use of practical assessments, interdisciplinary learning environments, workplace projects and industry case studies. This is followed by a discussion of key learnings of the project's efforts to embed energy efficiency within higher education engineering curriculum, based on insights gained through three external evaluations in 2011, 2012 and 2013, spanning government agencies, academic institutions, and academia. Given the word limit of this paper, individual project evaluation methodologies (i.e. including piloted course statistics, student evaluations of piloted course content etc), are not presented. It is intended that sharing project-level lessons about targeted curriculum development will contribute to literature in the field of education for sustainability and 
assist other organisations in Australia and overseas who are considering programs to build professional capability in emergent topics or other professions.

\section{Project Details}

In 2011 as part of a state-based competitive grant scheme the NSW government's Office of Environment and Heritage (OEH) awarded two leading NSW universities funds to develop energy efficiency courses for engineers at undergraduate (UG), postgraduate (PG) levels, as well as continuing professional development (PD). These details are summarised in Table 1.

Table 1. Summary of institutional agreement (OEH Website)

\begin{tabular}{|c|c|c|}
\hline University details & Courses* & Course content \\
\hline $\begin{array}{l}\text { University of } \\
\text { Wollongong } \\
\text { Funding amount: } \\
\text { AU } \$ 600,000\end{array}$ & $\begin{array}{l}5 \text { UG } \\
9 \mathrm{PD}\end{array}$ & $\begin{array}{l}\text { This project took into account user perceptions and } \\
\text { behaviour to maximise adoption of energy efficient } \\
\text { technologies, focusing on electricity generation, } \\
\text { transmission and distribution, demand side } \\
\text { management and built environment and industry. }\end{array}$ \\
\hline $\begin{array}{l}\text { University of New } \\
\text { South Wales } \\
\text { Funding amount: } \\
\text { AU } \$ 544,000\end{array}$ & $\begin{array}{l}8 \text { UG/ PG } \\
1 P D\end{array}$ & $\begin{array}{l}\text { This project developed courses focused on critical } \\
\text { concepts of energy efficiency in the design, } \\
\text { manufacturing and operation of engineered systems, } \\
\text { strategies to implement and measure improvements in } \\
\text { embodied and operational energy efficiency and } \\
\text { Minimum Energy Performance Standards (MEPS). }\end{array}$ \\
\hline
\end{tabular}

* (UG) undergraduate, (PG) postgraduate, (PD) continuing professional development

\subsection{Project structure}

Figure 2 summarises the innovative project structure, which involved a variety of partners including the $\mathrm{OEH}$, the two successful universities (University of New South Wales and the University of Wollongong), and an external evaluation consultant (Urbis). An external technical industry panel provided an advisory role to the $\mathrm{OEH}$ in particular on the initial funding decision and provided input on the design of the courses and a number of internal experts within $\mathrm{OEH}$ assisted with technical review regarding the proposed energy efficiency related knowledge and skills to be embedded within the curriculum. Industry engagement by the universities assisted with the design, development and delivery of courses, and an external curriculum review consultant (The Natural Edge Project) provided guidance on pedagogy and course content. 


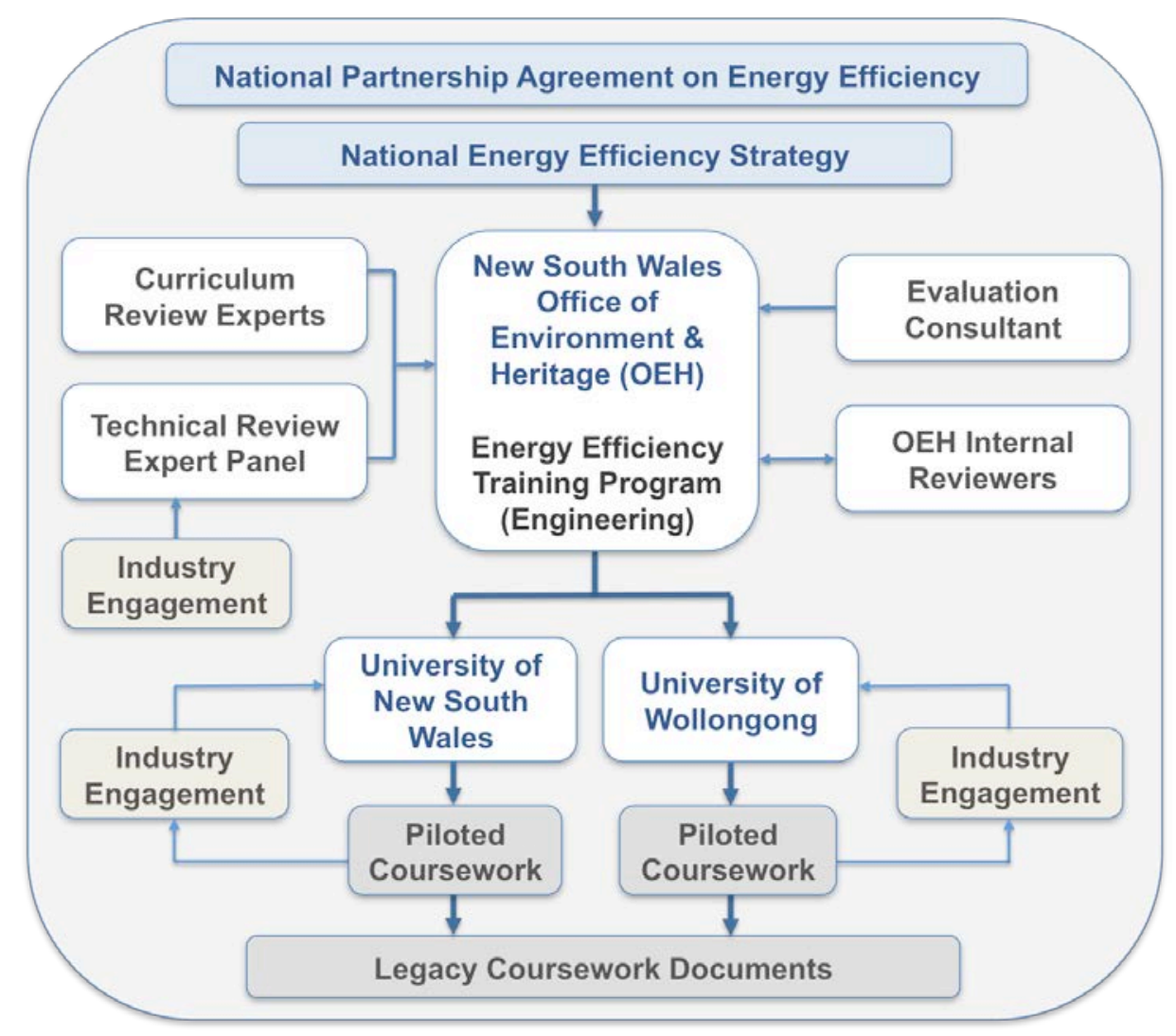

Figure 2. Illustration of the project organisational structure

\subsection{Evaluation of the Higher Education Energy Efficiency Engineering Project}

An important component of this innovative project was the inclusion of an externally managed evaluation process (by Urbis) alongside the course development, which included two facilitated workshops. The initial evaluation workshop at the commencement of the two projects (February 2011) brought the two successful universities together with the external technical industry panel to develop the key performance indicators for their projects, including short, medium and long-term considerations. Following this workshop each university project team developed an Evaluation Framework, to use throughout the project. The second evaluation workshop at the end of the projects (December 2012), comprised the two universities meeting together with $\mathrm{OEH}$ to reflect on the whole project, and each university also reflecting on their specific experiences and performance indicators separately to $\mathrm{OEH}$.

It is noted that the project included a number of internal-in confidence indicators for tracking progress, which were developed in the first workshop, used throughout and reflected on in the final workshop. This paper distills the key learnings from this process to contribute to the field of inquiry into rapid curriculum renewal.

\subsection{Project deliverables}


The project comprised several stages whereby course materials were drafted in consultation with industry and the state government, reviewed by a curriculum consultant, then piloted and subsequently refined. A summary of the courses produced provided in Table 2. It is noted that the courses developed by each institution fit within existing course work and within a larger vision of energy efficiency and sustainability education. Hence, the list in Table 2 is not a comprehensive summary of energy efficiency or sustainability topics.

Table 2: Summary of the courses developed under the training project

\begin{tabular}{|c|c|}
\hline Delivery* & Course Title \\
\hline \multicolumn{2}{|c|}{ University of Wollongong } \\
\hline UG & Renewable and Embedded Generation \\
\hline UG & Energy Efficiency in Electricity Utilisation \\
\hline UG-PG & Advanced Building Design for Energy Efficiency and Sustainability \\
\hline UG-PG & Energy Efficiency and Energy Auditing in the Built Environment \\
\hline UG-PG & Energy Efficiency in Manufacturing and Process Industries \\
\hline PD & Energy Efficiency in Electrical Energy Utilisation \\
\hline PD & Electricity Network Energy Efficiency Enhancement \\
\hline PD & Renewable and Distributed Generation \\
\hline PD & Smart Metering and Demand Side Management \\
\hline PD & Energy Auditing and Efficiency in Industrial Systems \\
\hline PD & Improving Energy Efficiency in Manufacturing and Industrial Processes \\
\hline PD & Energy Efficiency Enhancement Through Retrofitting of Commercial Buildings \\
\hline PD & Energy Auditing and De-Carbonisation of the Built Environment \\
\hline PD & Energy Efficiency Enhancement in Domestic Buildings \\
\hline \multicolumn{2}{|c|}{ University of New South Wales } \\
\hline UG-PG & Life Cycle Engineering \\
\hline UG-PG & Operational Energy Efficiency \\
\hline UG-PG & Energy Technologies and Infrastructure \\
\hline UG-PG & Distribution and Smart Grids \\
\hline UG-PG & Energy Efficient Lighting and Electrical Equipment \\
\hline UG-PG & Storage and Alternative Generation \\
\hline UG-PG & Efficiency in the Water Sector \\
\hline UG-PG & Design Studio for High Performance Buildings \\
\hline PD & Minimum Energy Performance Standards (MEPS) workshop \\
\hline
\end{tabular}

* (UG) undergraduate, (PG) postgraduate, (PD) continuing professional development

On completion of the project, components of the courses were made freely available online, creating a legacy of energy efficiency documents for undergraduate, 
postgraduate and continuing education, across a spectrum of highly topical areas. This included:

$\Rightarrow$ Course outlines: a detailed description of the course including learning outcomes, topics covered, staging of the topics, and assessment.

$\Rightarrow$ Course teaching guides: a summary document for academics considering using the coursework developed in this project, discussing intentions of the course, lessons learned through the piloting process and opportunities for assessment.

$\Rightarrow$ Online platform (UNSW): a 'Moodle' platform containing the full course, that could be accessed by academics where Moodle software is enabled in their institutions.

$\Rightarrow$ Course slides: lecture notes in the form of detailed PowerPoint slides that correspond to the topics within the Course Outline.

\section{Examples of Coursework Outcomes}

A key feature of this project was innovation by the universities in designing curriculum for complex and emergent energy efficiency topics. The following paragraphs summarise a selection of examples including the use of practical assessments, interdisciplinary learning environments, workplace projects and industry case studies.

\subsection{University of New South Wales}

The courses developed at UNSW were aimed at making available a wide range of "energy efficiency" course offerings across the Engineering faculty. This project greatly helped to raise the profile of energy efficiency across a range of engineering disciplines. The courses were primarily aimed at postgraduate coursework programs but were also offered to senior undergraduate students. Additionally the courses were structured so that they could be broken down into components and offered as professional development courses to industry professionals. UNSW has had a long and close involvement with industry, particularly in research. This project drew upon many of those strong links to industry and involved guest lecturers from a range of industry professionals, not only in delivery of guest lectures but also in planning the courses.

An example of this approach was the 'Integrated Design Studio for High Performance Buildings' course, which has students from engineering, architecture and sustainable development working together to bring their perspectives together early in the design process, so that engineering solutions can be built into a more optimised design, rather than added as an afterthought. The course involved about 60 postgraduate students from the Faculty of the Built Environment (Sustainable Development students) and postgraduate students and senior undergraduate students from the Faculty of 
Engineering (Photovoltaic and Renewable Energy Engineering, Mechanical

Engineering, Electrical Engineering) working in teams to design a high performance, low energy building.

The brief given to the student teams was based on the actual brief for the new Material Science building at UNSW. As such the students found themselves grappling with a very real world project. Industry professionals were involved in regular guest lectures for the first eight weeks of the course, as well as in tutoring the students as they developed their designs. This mix of industry professionals, academic staff and students across a range of disciplines was new for many involved in the class and much of the learning involved students learning to appreciate the different skills and "language" of their fellow team members. The culminating designs were presented and critiqued by industry professionals. Many students commented about how much they gained technically and professionally from such a multidisciplinary course.

\subsection{University of Wollongong}

At UOW, this project was a significant trigger for energy efficiency education, where prior to the project there were no courses in the engineering faculty focusing on energy efficiency. Course development and delivery was broken into two stages. The first stage included five professional development courses, while the second stage consisted of four such courses and five undergraduate/ postgraduate (UG/PG) subjects. The development of professional development courses prior to UG/PG allowed for some transfer of general materials and establishment of industry state-ofthe-art for the undergraduate program, and also assisted in developing the (practical) knowledge of the academics involved.

UG/PG subjects were developed with pedagogy typical to other elective units, in addition to an increased level of practical (industry) processes within materials and assessment items where possible. Professional development courses focused on industry relevance, interactive delivery and drew on participant experience, generally delivered to a broad array of participants over two days. Where relevant, some courses were delivered on-site direct to a specific industry, e.g. electricity network energy efficiency, which allowed for a shorter timeframe for delivery. The courses attempted to deliver a mix of design principles, standards and legislative requirements (where applicable). Demonstration of technology application through case studies was a key desirable outcome identified by participant feedback.

Real case studies were included in all professional development courses. Materials for case studies were developed (with review by UOW academic team) and delivered by industry personnel, which assisted in emphasising the practical aspects of 
implementing energy efficiency initiatives. Case studies based around a holistic approach to energy efficiency were selected which emphasised the benefits of including energy efficiency considerations into initial plant design, capital upgrades, and maintenance and operating procedures. Behavioural factors related to energy efficiency were also included in professional development courses and UG/PG subjects. This included for example technology adoption, potential to adjust the parameter boundaries of human factors related to thermal comfort (separation of pressure and flow), etc. Feedback from early stage professional development pilots identified additional considerations, which were included in later pilots.

Assignment activities for the built environment UG/PG courses included analysis using the "house with no steps", a local charitable organisation, as a case study. Students had to propose and analyse energy efficiency retrofits for an upgrade to this charitable organisation's headquarters. The UOW solar decathlon project, whereby students design and construct a solar powered energy efficient house as part of an international university competition, was also utilised as a multi-level case study. Individual components and operation of the house were analysed in assignment activities of the UG/PG courses. Applicable software tools were also introduced in the professional development courses and UG/PG courses to provide delegates with some hands-on design and retrofit evaluation analysis. While undergraduate students found this typical to their existing undergraduate program, professional development delegates found this very beneficial and atypical for this style of course.

For a number of undergraduate courses, workshop styled classroom activities directed towards solving "real world" problems were delivered in place of normal lectures.

Students worked in groups, defining specifications, justifying assumptions, understanding constraints, and preparation and submission of documentation. This allowed students to develop the theory (based on their existing knowledge) necessary for applying energy efficiency initiatives and solving other engineering problems. An emphasis was placed on demonstrating the advantage of taking a holistic approach. Such workshops were encouraged by both the industry advisory groups and OEH. Attendance in UG/PG courses was generally high and comparable to existing "popular" offerings within undergraduate and postgraduate programs. Feedback obtained from course evaluations indicated that students believed energy efficiency will be an important aspect of their career.

\section{Discussion of Key Learnings}

Through the evaluation workshops and in follow-up communications with the author team, project participants reflected on their experiences. A number of learnings were 
distilled with regard to working in partnership to deliver energy efficiency education, applying insights from the literature referred to in the introduction to large-scale multiinstitutional content development. These learnings are discussed under the following headings, which summarise the learnings in the form of suggestions for future initiatives:

1. Address undergraduate, postgraduate and professional needs.

2. Ensure early industry involvement in course development.

3. Foster a real world learning and teaching environment.

4. Align projects to university curriculum renewal processes.

5. Include clear expectations for reporting and partnerships.

6. Provide flexibility in budget and deliverables.

7. Embed feedback and evaluation within the project.

The first three learnings build on a considerable amount of literature on contextually relevant curriculum renewal in engineering education, discussed briefly in the introduction. The remaining four learnings relate to funding provision and management, on which there is relative absence of literature. All of these learnings provide provocation for further exploration in future curriculum development projects in engineering and other higher education disciplines.

\subsection{Address undergraduate, postgraduate and professional needs}

Education for sustainability literature includes many references to staff resourcing, pedagogical and organizational benefits (such as co-offering coursework, developing curricula for multiple audiences) from a whole of education approach to curriculum development that spans undergraduate, postgraduate and professional needs (for example Byrne et al, 2013; Holmberg and Samuelsson, 2005). However there is not a clear preference for the order in which such curriculum renewal should occur, or cautionary advice for embarking on such curriculum renewal.

This project was designed to address multiple education needs, from undergraduate to postgraduate and professional development, encouraging exposure by engineers to energy efficiency at an early stage of education with a longer-term focus, in addition to catering for practicing engineers seeking knowledge and skills for immediate application in the workplace.

With regard to the order of curriculum renewal, project team members considered that the best way to get industry input into undergraduate courses was to do professional development courses first because undergraduate curriculum is much harder to develop materials for and harder to attract students to. Discussions with industry were 
primarily around professional development courses and the desired outcomes, which then fed into the undergraduate courses.

Considering the content of the curriculum renewal and in particular requirements for student reading, supplementary materials for the courses were quite limited, including a noted absence of appropriate textbooks or online supporting resources on the desired topic areas. It is anticipated that this will improve as higher education in these topic areas expands. The two universities subsequently relied on a longer list of readings taken from a variety of materials rather than a specific supporting resource for each course.

Engaging with a wide variety of audiences for such energy efficiency related topic areas (i.e. from undergraduate through to practitioners), an additional reflection was that in piloting the professional development courses, it was challenging for academics to relate to non-engineering participants. This highlighted the need for new courses in energy efficiency to be clear about any pre-requisite training or assumed prior knowledge for courses in such rapidly emergent topic areas, to ensure that participants - undergraduate or postgraduate - get the most out of their studies.

With the substantial amount of coursework developed and project management related learnings, an additional idea generated during the project evaluation included the possibility of embedding dissemination funding (i.e. to reach more academics and subsequently a larger potential student cohort) in future projects' scope. Project participants commented that conference presentations and workshops tied to existing events could be an effective means to target large audiences, rather than standalone energy efficiency events. It was noted that these would need to be targeted at professionals and practitioners in addition to academics. Within this project, online documents were seen to be the most effective way of disseminating coursework documents, with each university considering website opportunities to promote and disseminate project materials.

\subsection{Ensure early industry involvement in course development}

Education for sustainability literature includes many references to the value and contribution of industry and professional bodies in curriculum renewal (for example Lozano and Lozano, 2014 in Mexico; Thomas et al, 2013 in Australia; Davidson et al, 2010, Allenby et al, 2009 and Counce, 2008 in America; Quist et al, 2006 in the Netherlands; and Holmberg and Samuelsson, 2005 and Byrne et al, 2013 internationally). Considering this literature, this project demonstrated the value of early and close industry engagement in the curriculum renewal processes, along with the opportunity for interdisciplinary collaboration (i.e. engineers and architects working 
together). In particular, sufficient time is required during the early stages of curriculum development to identify the target audience and understand their learning needs. In this project, such involvement brought people together and helped academics better understand the business case for energy efficiency. Industry reference groups provided input to course design, with even more involvement suggested possible in future projects. One challenge observed, is in understanding the diversity of 'energy efficiency' as a topic, and government priorities on various sectors (such as manufacturing), to then provide specific up-skilling. Industry partners were valuable in identifying potential energy efficiency industry contacts where academics did not necessarily have personal connections.

Facilitated collaboration with industry also provided valuable insights into the right language for the audience, and the business objectives and context needed for course material to have real world relevance. In particular Industry were interested in case study material that covered areas including: who were the stakeholders; how the project was justified; what as the direct and in-direct return on investment; what financial and non-financial assistance was sought/received; how was the project implemented; and what were the outcomes relevant to industry in Australia.

Both universities found it challenging to get sufficient practicing engineers to attend the piloted professional development courses. Knowledge of the availability and mix of capability of the target cohort required more consideration at initial stages of project, but improved with experience. The topics, timing, and structure of professional development courses need to be carefully considered to entice industry to attend. This can be achieved by offering industry participants in courses a recognised learning towards higher education, such as recognition as a unit in a post graduate certificate, Masters or other relevant industry programs.

Both project teams suggested a greater level of interaction with professional bodies and associations to compliment industry engagement. The value of such interaction includes: access to membership for peer review and expert support; opportunity to align coursework to professional accreditation requirements and standards; access to networks to promote professional development course offerings; potential venues for industry training sessions; and to identifying potentially competing training offerings (that is best identified early to avoid a reluctance to participate):

\subsection{Foster a real world learning and teaching environment}

Education for sustainability literature is usually prefaced by the critical need for such curricula to imbue current global context (see in particular Lozano and Lozano, 2014; Thomas et al, 2013 in Australia; Davidson et al, 2010 in America; Quist et al, 2006 in 
the Netherlands; and as far back as Velazquez et al, 1999 in Mexico). More recently there has been an increase in discussion on the value of contextually appropriate problem or project based learning in curriculum renewal towards education for sustainability (for example Lehmann et al, 2008).

Both universities received feedback as part of their course pilots that the courses should foster a real world learning and teaching environment. In particular the professional development components of both projects faced the challenge to meet the needs of practicing engineers with regard to building capacity to respond to immediate energy-efficiency related problems and identify tangible, cost effective solutions. Four strategies were considered by participants to be particularly important:

$\Rightarrow$ Engaging industry in teaching: Engaging with experienced industry professionals to co-deliver courses, or provide guest lecturers, enabled students to access real world experience in the classroom and see the immediate application of the knowledge and skills in the course. This arrangement also helped to address differences in the background of academics, where industry expertise could complement the academic's expertise and in some cases provide professional development opportunities in new and emerging topic areas for the academics involved.

$\Rightarrow$ Providing a business context for energy efficiency: Providing a business context for the coursework helped make it 'real world' and encouraged understanding of its practical application. This included using terminology that positioned energy efficiency as a component of cost efficiency, productivity, competitiveness, business strategy and leadership.

$\Rightarrow$ Creating opportunities for participant networking: Interactive sessions during the piloted courses were very successful, enabling students to share their expertise with each other and become familiar with various industry applications of the topics being discussed. For online delivery of courses, participants noted that technology would need to be explored to achieve a similar outcome.

$\Rightarrow$ Offering participants articulation opportunities within higher education: Where possible, coursework was offered that had the potential to lead to a formal qualification. There was some student feedback indicating that attaching credit points to the courses would make courses more desirable, so that they could contribute towards an associated qualification.

\subsection{Align projects to university curriculum renewal processes}


Curriculum renewal literature (including education for sustainability literature) contains only incidental references to how government funded targeted-programs can support curriculum renewal processes, usually with regard to which topics should be supported (for example Byrne et al, 2013 considering the international context; and Counce, 2008 considering industry and government perspectives) and the type of programs that could be supported (for example Allenby et al, 2009 and Ashford, 2004 with regard to the American experience).

However, one of the key challenges that faced both university project teams was about sequencing tasks so that project milestones aligned with institutional timeframes for curriculum renewal. This included for example: school and faculty board meetings; course outline review processes; and university semesters. Special sittings of various committees were held in some cases to expedite reviews and approvals. This was necessary as the approval processes in some instances required external body review, including school industry advisory committees and Engineers Australia, and the curriculum approval committees only sit at fixed and infrequent times throughout the year.

A further difficulty in the UOW project was that some of the newly funded personnel did not come on board until later in project, e.g. only months before the proposed pilot delivery of the first undergraduate subject. Allowing suitable time in the project to fill funded positions was an area that required careful consideration, noting government agencies typically have short-term deadlines associated with funding availability. The length of the project (i.e. two years) was beneficial in spanning several university semesters, also enabling academics to undertake curriculum renewal activities in the semester breaks, and schedule course pilots allowing adequate time for promotions and registrations.

\subsection{Include clear expectations for reporting and partnerships}

In addition to sequencing considerations discussed above, the project participants were challenged by reporting requirements in this project. Regular reporting from the universities included details about curriculum development in addition to the usual progress reports. This assisted OEH in managing two large higher education institutions generating many new and updated courses and created transparency in the project's process. However during evaluation, project participants did note that the reporting structure was quite different to the rather autonomous style of grant reporting that project team members were used to. This created some additional resourcing requirements for each institution to 'standard' project management measures. 
The tendering documents for this project included a clear expectation for engagement with industry partners, to ensure workplace relevance of the coursework materials. Participants found the requirement to involve industry (in design/ development) was a good opportunity for engagement. During the evaluation, participants commented that perhaps more formal contracting approaches (i.e. a contractual agreement with each partner rather than a letter of intent/in-kind support) could have been considered in the applications phase to further emphasize the importance of, and secure, industry involvement.

\subsection{Provide flexibility in budget and deliverables}

Building on the learnings with regard to reporting and alignment of milestones discussed above, project participants identified three innovative components in relation to flexible budgeting for curriculum renewal and delivery:

- Budget for project administration and coordination: In this project it was noted that allocating dedicated project managers to coordinate and facilitate project management across the range of courses provided valuable support to the academics developing the courses. It also enabled the point of contact to manage the feedback process with academics and complete the associated documentation regarding edits. Project participants suggested that in future programs efforts be made to reduce the administrative load to manage and deliver the projects, along with streamlining project paperwork and administration for the application and reporting processes.

- Facilitate innovation in deliverables: Given the emergent nature of the content and the extensive collaboration needed to develop new courses, project participants noted the need for flexibility in demonstrating deliverables, i.e. allowing delivery on intent instead of the complete detail of deliverables, which could enable adaptability as the project unfolds. For example, one of the projects originally considered precourse reading material for industry participants, however based on industry feedback this element was not developed, with efforts focused on other areas.

- Facilitate innovation in timeframes: Project participants suggested a greater focus on achieving flexible funding agreements to allow some adaptability in milestone/ deliverables during the development phase. Participants noted that more flexibility in budgeting could be beneficial, as at times project timeframes and milestones limited the flexibility of projects to adapt and tailor the course materials along the process according to specific participant needs and feedback.

\subsection{Embed feedback and evaluation within the project}


Within curriculum renewal literature, there is some discussion about methods for feedback and evaluation within environmental education discourse (for example Thompson and Hoffman, 2003; Fisher, 2010). However, there are few cases of documenting education for sustainability project or program level evaluations, considering opportunities to learn from implementation experiences. This project used a formal evaluation process that included both course level evaluation and project level evaluation. At the level of coursework project participants found detailed, written feedback useful, particularly early on during the design stage. The tabulated format of feedback (requiring both institutions to document their responses) was an additional layer of reporting was found to provide transparency in how review comments had been addressed. The inclusion of external technical and curriculum reviewers was also noted as beneficial, perhaps more so at the commencement of the project when the courses were being conceptualized and shaped.

With regard to feedback on project delivery, project participants noted during evaluation that they appreciated that OEH followed up on deliverables, which helped keep project management on track. Given that the project evaluation included a 'long term' outlook component, participants reflected that perhaps in future projects there could be a longer-term commitment to evaluate the impacts of the projects (e.g. take-up of the courses at the two universities and online materials).

\section{Conclusions and Implications for Future Programs}

The Energy Efficiency Training Program supported the development and delivery of higher education engineering courses that enhance energy efficiency knowledge and practice. This included work with universities and industry to ensure key sectors have access to professional development, as well as undergraduate and postgraduate courses in energy efficiency and renewable energy. In its successful completion, the project provides a number of key learnings for working in partnership to develop engineering capability in energy efficiency, related to ensuring industry-relevant coursework and delivery, and managing discrete projects within complex curriculum renewal processes.

\subsection{Industry-relevant courses and delivery}

The project demonstrated the importance of identifying the target audience for courses and the best ways for this audience to learn, then adapting approaches accordingly. This project demonstrated that information on energy efficiency can be imparted to industry through partnering with higher education. While it was difficult to determine the impact of the courses on engineering capability within the evaluation undertaken for this 
project, the courses provided accessible documents for other universities to use in their own programs. The initiative has also developed industry connections with two large universities in New South Wales.

Given industry needs are a major driver for energy efficiency education this project demonstrated the value of industry playing a core role in the design and delivery of associated courses. This is an important aspect of curriculum development as it goes beyond the usual scope of industry providing advice to universities on high level directions within particular sectors and allows direct contribution to course development, delivery, and assessment to link topics and concepts to industry practice.

The balance and design of course delivery between online and face-to-face modes is a key challenge in the course design process, with the delivery mode needing to be flexible to allow elements such as interactive activities and assignments, group work and networking. This is particularly so for courses catering to continuing professional development rather than undergraduate or postgraduate studies.

A significant positive outcome from the project is improved links and networks between the two partner universities and industry, at both the state and national level. Both universities also have a stronger understanding of industry needs and the breadth of issues facing particular industry sectors. Given the rapidly changing context for industry, speakers who can explain the history and context for changes to legislation and funding options for energy savings play a core role in keeping coursework industry relevant. Industry and professional associations will also have experience, insights and connections relevant to how such courses can be communicated, marketed and disseminated.

\subsection{Managing curriculum projects within complex academic processes}

This project demonstrated the value of implementing discrete curriculum renewal projects within complex existing curricula. Following this level of integration of energy efficiency into targeted undergraduate courses, the project has opened up the possibility for such content from these courses to subsequently be integrated into mainstream engineering education in the coming years.

In this project, success in achieving buy-in from the universities to engage in curriculum renewal on this scale relied on champions within each of the universities to drive the project. The project created a core group of people who were hired and/or funded to develop energy efficiency courses. This group then engaged with other faculty who are now also becoming involved in developing and delivering energy efficiency coursework. A multi-disciplinary focus in courses also provided a valuable opportunity to bring together professionals who are required to interact in the workforce, and created 
opportunities to discuss university cross-faculty teaching joint-masters that include for example energy efficiency engineering courses with some accounting.

It is noted that there were some challenges in setting up these discrete projects, including separate evaluation needs, where not all students completed the additional evaluation requirements. Setting up professional development courses separately to normal masters level courses was also challenging at times.

\subsection{Implications for future programs}

This project has demonstrated the power of collaborative leadership between government, industry and higher education in driving the energy efficiency agenda. The courses have contributed to increased awareness and momentum in this early stage of this topic among universities and industry, demonstrated the potential for strong industry linkages to assist in curriculum renewal, and contributed to the ongoing development of an energy efficiency community/ network. It is expected that this momentum will continue to build in coming years, with strong support among project proponents for broad dissemination of the project outputs and the learnings described in this paper.

Looking forward to future project opportunities for curriculum renewal, there is a need for long-term planning for energy efficiency education - within higher education, government and industry - as this is an evolving topic where there will continue to be new knowledge and skills to be integrated. This includes all sectors having a sustained interest in emergent standards and legislation, government programs and funding frameworks, to take advantage of curriculum development and funding opportunities as they arise.

Following up with regard to this project, a future study of participants who were involved in this project (for example one or more years after exposure) could help to evaluate the impact of the courses on their professional careers. This would be of use to colleagues in the field involved with curriculum development and delivery for Sustainable Development and could also provide the initiative with evidence of impact for follow on funding.

Further to the success of this program there is a need for more government funding for curriculum renewal to be made available in a similar capacity. Given the prestige associated with research grant acquisition within higher education institutions, such funding avenues connect in quickly with academics who can then undertake education research while producing renewed curriculum as one of the outputs. Partnerships and relationships established through the projects could also be used to establish cross- 
university collaboration on engineering research in energy efficiency, which would encourage broader engagement across a range of universities.

The project has also highlighted the need for greater academic linkages with industry. This could be supported for example through academic internships in industry to keep up to date with new technology and needs of industry, increasingly involving industry in course design to ensure relevance, industry guest lectures and the use of industry based practical assessments.

\section{Acknowledgements}

The first author discloses their role in the project as the curriculum review consultant (The Natural Edge Project), and that funds were received from $\mathrm{OEH}$ to lead the writing of this paper, including editorial input from $\mathrm{OEH}$. The second and third authors disclose their involvement as leading researchers within the two university projects. The authors would like to acknowledge the contributions to the projects from $\mathrm{OEH}$, Urbis Consulting, academics from the University of New South Wales, University of Wollongong, and The Natural Edge Project, along with the Expert Review Panel comprising a number of individuals who provided pro-bono review of the courses documents at several stages during their development. The authors would also like to thank the following individuals for their review contributions in this paper development: Ms Clare Donovan, Ms Katy Christian, and Ms Frouke de Reuver.

\section{List of acronyms}

$\begin{array}{ll}\text { COAG } & \text { Council of Australian Governments } \\ \text { NFEE } & \text { National Framework for Energy Efficiency } \\ \text { OEH } & \text { New South Wales } \\ \text { PD } & \text { Office of Environment and Heritage } \\ \text { PG } & \text { Professional Development } \\ \text { RET } & \text { Postgraduate } \\ \text { UG } & \text { Federal Department of Resources, Energy and Tourism } \\ \text { UNSW } & \text { University of New South Wales } \\ \text { UOW } & \text { University of Wollongong }\end{array}$

\section{References}


Abdul-Wahab, S., Abdulraheem, M., and Hutchinson, M. 2003. The need for inclusion of environmental education in undergraduate engineering curricula. Int. J. Sust. Higher Ed. 4, 2, 126-137.

Allenby, B., Folsom Murphy, C., Allen, D., and Davidson, C. 2009. Sustainable engineering education in the United States. J. Sust. Science. 4, 1, 7-15.

Thomson, G., Hoffman, J. 2003. Measuring the success of environmental education programs. Canada: Network for Environmental Education.

Ashford, N. 2004. Major challenges to engineering education for sustainable development: What has to change to make it creative, effective, and acceptable to the established disciplines? Int. J. Sust. Higher Ed. 5, 3, 239-250.

Alshuwaikhat, H., and Abubakar, I. 2008. An integrated approach to achieving campus sustainability: assessment of the current campus environmental management practices. J. Clean. Prod. 16. 1777-1785.

Azapagic, A., Perdan, S., and Shallcross, D. 2005. How Much Do Engineering Students Know about Sustainable Development? The Findings of an International Survey and Possible Implications for the Engineering Curriculum. Euro. J. Eng. Ed. 30, 1, 1-19.

Barth, M., and Rieckmann, M. 2012. Academic staff development as a catalyst for curriculum change towards education for sustainable development: an output perspective. J. Clean. Prod. 26, 28-36.

Boks, C., and Diehl, J. 2006. Integration of sustainability in regular courses: experiences in industrial design engineering. J. Clean. Prod. 14, 9, 932-939.

Byrne, E., Desha, C., Fitzpatrick, J., and Hargroves, K. 2013. Exploring sustainability themes in engineering accreditation and curricula. Int. J. Sust. Higher Ed. 14, 4, 384-403.

COAG. 2009a. National Partnership Agreement on Energy Efficiency, Council of Australian Governments, 3.

COAG. 2009b. National Strategy on Energy Efficiency, Council of Australian Governments, Canberra.

Counce, R., 2008. University partnerships with Industry and Government. Int. J. Engng Ed. 24, 3,480 .

Davidson, C., Hendrickson, C., Matthews, H., Bridgesc, M., Allend, D., Murphy, C., Allenby, B., Crittendenf, J. and Austing, S. 2010. Preparing future engineers for challenges of the 21st century: Sustainable engineering. J. Clean. Prod. 18, 7, 698-701.

DEEWR., n.d. The Clean Energy and Other Skills Package - Information Sheet, Canberra.

Desha, C. and Hargroves, K. 2014. Higher Education and Sustainable Development: A Guide to Curriculum Renewal, The Natural Edge Project, Earthscan: Routledge, London.

Desha, C., and Hargroves, K. 2009. Surveying the State of Higher Education in Energy Efficiency in Australian Engineering Curriculum. J. Clean. Prod. 18, 7, 652-658. 
Desha, C., Hargroves, K., and Reeves, A. 2009. Engineering Curriculum Renewal for Energy

Efficiency: Barriers and Benefits Analysis, Report to the National Framework for Energy

Efficiency, The Natural Edge Project (TNEP), Australia.

Fernández-Viñé, M.B., Gómez-Navarro, T., and Capuz-Rizo, S.F. 2013. Assessment of the public administration tools for the improvement of the eco-efficiency of small and medium sized enterprises. J. Clean Prod. 47, 265-273.

Fisher, Y. 2010. Measuring success: Evaluating educational programs. US-China Ed Review. 7, $6,67$.

Glavic, P. 2006. Sustainability engineering education. Clean Techn Environ Policy. 8. 24-30.

Holmberg, J. and Samuelsson, B. (Eds.). 2005. Drivers and Barriers for Implementing Sustainable Development in Higher Education. Available at http://unesdoc.unesco.org/images/0014/001484/148466E.pdf (accessed 30.10.13).

Karatzoglou, B. 2013. An in-depth literature review of the evolving roles and contributions of universities to Education for Sustainable Development. J. Clean. Prod. 49, 44-53.

Kastenhofer, K., Lansu, A., Van Dam-Mieras, R., Sotoudeh, M. 2010. The contribution of university curricula to engineering education for sustainable development. 19, 1, 44-51.

Koester, R., Eflin, J. and Vann, J. 2006. Greening of the campus: a whole-systems approach. J. Clean. Prod. 14, 769-779.

Lehmann, M., Christensen, P., Du, X., and Thrane, M. 2008. Problem-oriented and projectbased learning (POPBL) as an innovative learning strategy for sustainable development in engineering education. Euro. J. Eng. Ed. 33, 3, 283-295.

Lozano, F., and Lozano, R., 2014. Developing the curriculum for a new Bachelor's degree in Engineering for Sustainable Development. J. Clean. Prod. 64, 136-146.

Lundholm, C. 2004. Learning about environmental issues in engineering programmes: A case study of first-year civil engineering students' contextualisation of an ecology course. Int. J. Sust. Higher Ed. 5, 3, 295-307.

OEH., n.d. New South Wales Office of Environment and Heritage website, www.environment.nsw.gov.au/sustainbus/greenskills/eneftraining.htm.

Quist, J., Rammelt, C., Overschie, M., and Werk, G. de. 2006. Backcasting for sustainability in engineering education: the case of Delft University of Technology. J. Clean. Prod. 14, 9, 868876.

RET., 2011a. Research Project 1 - Energy Efficiency Graduate Attributes Project, Queensland University of Technology, report to the Energy Efficiency Advisory Group, Department of Resources, Energy and Tourism, Canberra.

RET., 2011b. Research Project 2 - Energy Efficiency Resources for Undergraduate Engineering Education, University of Adelaide, report to the Energy Efficiency Advisory Group, Department of Resources, Energy and Tourism, Canberra. 
RET., 2012. Consultation: Energy Efficiency and Engineering Education. Report to the Energy Efficiency Advisory Group, Department of Resources, Energy and Tourism, Canberra.

Segalàs, J.; Ferrer-Balas, D.; Mulder, K. F. 2010. What do engineering students learn in sustainability courses? The effect of the pedagogical approach. J. Clean. Prod. 18, 3, 275-284.

Svanstrom, M., Palme, U., Wedel, M., Carlson, O., Nystrom, T., Eden, M. 2012. Embedding of ESD in Engineering Education: Experiences from Chalmers University of Technology. Int. J. Sust. Higher Ed. 13, 3, 279-292.

Thomas, I., Barth, M., and Day, T. 2013. Education for Sustainability, Graduate Capabilities, Professional Employment: How they all Connect, Aust. J. Env. Ed. 29, Special Issue 01, 33 - 51.

Velazquez, L., Munguia, N., and Romo, M. 1999. Education for sustainable development: The engineer of the 21st century. Euro. J. Eng. Ed. 24, 4, 359-370.

Weisacker, E., Hargroves, K., Smith, M., Desha, C., Stasinopoulos, P. 2009. Factor 5:

Transforming the Global Economy through 80\% Improvements in Resource Productivity.

Earthscan, London.

Wiek, A., Withycombe, L., Redman, C. 2011. Key competencies in sustainability: A reference framework for academic program development. J. Sustain Sci. 6, 2, 203-208. 